\title{
Efeitos da amitriptilina sobre a modulação da dor aguda, em ratos submetidos à ligadura do nervo ciático*
}

\author{
Amitriptyline effects on acute pain modulation in rats submitted to sciatic nerve ligation \\ Naira Correia Cusma Pelógiaํㅜㄹ Bruna Gouvea Machado², Francielly Capelete Briet de Almeida², \\ Elton Constantino ${ }^{3}$, Oscar César Pires ${ }^{4}$ \\ * Recebido da Universidade de Taubaté. Taubaté, SP.
}

\section{RESUMO}

JUSTIFICATIVA E OBJETIVOS: Diversos sistemas de receptores estão envolvidos na modulação central da dor: noradrenérgico, serotoninérgico e opioide, entre outros. O objetivo foi estudar os efeitos da amitriptilina sobre a modulação da dor em ratos, após ligadura do nervo ciático.

MÉTODO: Foram estudados 24 ratos Wistar, machos, com peso médio de $300 \mathrm{~g}$, distribuídos em 5 grupos: (C) controle sem tratamento $(\mathrm{n}=4)$, (LC) submetidos à ligadura do nervo ciático $(\mathrm{n}=5)$, submetidos à ligadura do nervo ciático e tratados com: $(\mathrm{A})$ amitriptilina $(\mathrm{n}=5)$, $(\mathrm{R})$ com reserpina $(\mathrm{n}=5)$, (AR) com reserpina + amitriptilina. Todos os animais foram submetidos ao teste da formalina modificado.

RESULTADOS: A ligadura do nervo ciático reduziu a resposta nociceptiva. O tratamento com reserpina não interferiu com a resposta álgica na fase 1 do teste da formalina. A amitriptilina restaurou a resposta álgica na fase 1 do teste da formalina, indicando potencialização da nocicepção periférica, e reduziu o número das elevações das patas durante a fase intermediária do teste da formalina, na ausência ou na presença de reserpina, indicando potencialização da resposta da via descendente

1. Farmacêutica, Professora Assistente Doutora de Fisiologia da Universidade de Taubaté. Taubaté, SP, Brasil.

2. Graduando em Medicina da Universidade de Taubaté.

Taubaté, SP, Brasil.

3. Médico Anestesiologista, Professor Assistente de Anestesiologia da Universidade de Taubaté. Taubaté, SP, Brasil.

4. Médico Anestesiologista, Professor Assistente Doutor de Farmacologia da Universidade de Taubaté. Taubaté, SP, Brasil.

Endereço para correspondência:

Naira Correia Cusma Pelógia

Rua Ipanema, 100 - Sapé I

12294-015 Caçapava, SP.

E-mail: cusmapelogia@gmail.com inibitória da dor. A ligadura do ciático reduziu a resposta na fase 2 do teste da formalina. A amitriptilina restaurou a resposta anteriormente observada.

CONCLUSÃO: O tratamento com amitriptilina e reserpina permite sugerir que no modelo de lesão neural periférica, a noradrenalina participa da transdução do sinal lesivo, na modulação da via descendente inibitória da dor e na nocicepção induzida pelo processo inflamatório. A participação dos outros mediadores da resposta inflamatória e da serotonina deve ser considerada.

Descritores: Amitriptilina, Dor, Neuropatia, Reserpina, Teste da formalina.

\section{SUMMARY}

BACKGROUND AND OBJECTIVES: Different receptor systems are involved with central pain modulation: noradrenergic, serotoninergic and opioid among others. This study aimed at evaluating amitriptyline effects on pain modulation in rats submitted to sciatic nerve ligation.

METHOD: The sample was made up of 24 male Wistar rats, mean weight of $300 \mathrm{~g}$, which were distributed in 5 groups: (C) control without treatment $(\mathrm{n}=$ 4), (LC) submitted to sciatic nerve ligation $(n=5)$, submitted to sciatic nerve ligation and treated with: (A) amitriptyline $(\mathrm{n}=5),(\mathrm{R})$ reserpine $(\mathrm{n}=5),(\mathrm{AR})$ reserpine + amitriptyline. All animals were submitted to modified formalin test.

RESULTS: Sciatic nerve ligation has decreased nociceptive response. Reserpine administration has not interfered with pain response in formalin test phase 1. Amitriptyline has restored pain response in formalin test phase 1 , indicating peripheral nociception potentiation, and has decreased the number of flinches during the intermediate formalin test phase, in the ab- 
sence or presence of reserpine, indicating potentiation of pain response inhibitory descending way. Sciatic nerve ligation has decreased response in formalin test phase 2 . Amitriptyline has restored previously observed response.

CONCLUSION: Treatment with amitriptyline and reserpine allows suggesting that in the peripheral neural injury model, norepinephrine participates in the injuring signal transduction, in the pain inhibitory descending way modulation and in the inflammation-induced nociception. The participation of other inflammatory response mediators and of serotonin should be considered.

Keywords: Amitriptyline, Formalin test, Neuropathy, Pain, Reserpine.

\section{INTRODUÇÃO}

A dor é um fenômeno neurobiológico complexo com uma variedade de fatores contribuindo para os mecanismos centrais e periféricos de sinalização ${ }^{1}$. A modulação nociceptiva descendente é realizada pela liberação de serotonina e noradrenalina na medula espinhal ${ }^{2}$.

Antidepressivos seletivos suprimem a dor por diferentes mecanismos e são considerados como componentes essenciais da estratégia para o tratamento de diferentes tipos de dor persistente ${ }^{3}$.

A reserpina diminui a noradrenalina e a serotonina cerebral, aumenta a reação à dor e acelera a tolerância à morfina ${ }^{4}$. A amitriptilina é um fármaco antidepressivo que tem sido utilizado para tratamento de dor persistente. Os mecanismos de ação envolvem a ativação da via descendente inibitória da dor pelo aumento da concentração de serotonina e de noradrenalina na fenda sináptica em níveis espinhal e supraespinhal ${ }^{1}$.

O objetivo deste estudo foi estudar os efeitos da amitriptilina sobre a modulação da dor em ratos, após lesão do nervo ciático.

\section{MÉTODO}

Após aprovação pelo Comitê de Ética em Experimentação Animal da Universidade de Taubaté (UNITAU) (CEEA/UNITAU 003/2009), realizou-se este estudo utilizando 24 ratos Wistar machos, pesando entre 300 e $350 \mathrm{~g}$, fornecidos pelo Biotério da UNITAU e mantidos em número de 5 animais por compartimento no laboratório de Farmacologia da UNITAU, onde permane- ceram por pelo menos 15 dias antes do início do experimento, para adequada adaptação, sendo permitido o acesso à ração balanceada comercial e água ad libitum. A luminosidade foi controlada com ciclo claro-escuro de 12 horas e a temperatura ambiente de $22 \pm 3^{\circ} \mathrm{C}$ $\left(19\right.$ a $\left.25^{\circ} \mathrm{C}\right)$. Para realização dos procedimentos experimentais foram obedecidas as Normas Éticas da International Association for Study of Pain (IASP), que regulam experimentos realizados em animais (Commitee for Research and Ethical Issues of the IASP, 1983). Somente animais com aspecto sadio foram utilizados na pesquisa.

Os animais foram aleatoriamente divididos em 5 grupos, de acordo com o tratamento farmacológico: grupo controle $(C)$ : sem tratamento $(n=4)$, grupo ligadura do ligadura do ciático (LC): os animais foram submetidos à lesão do ciático $(\mathrm{n}=5)$, grupo reserpina $(\mathrm{LC}+\mathrm{R})$ : os animais foram submetidos à lesão do ciático e tratados com reserpina $5 \mathrm{mg} / \mathrm{kg}$ por via oral (VO) em intervalos de $72 \mathrm{~h}$, durante 15 dias $(\mathrm{n}=5)$, grupo amitriptilina $(\mathrm{LC}+\mathrm{A})$ : os animais foram submetidos à lesão do nervo ciático e tratados diariamente com amitriptilina $5 \mathrm{mg} / \mathrm{kg} \mathrm{VO}$, durante 15 dias (n =5) e grupo amitriptilina + reserpina (LC+AR): os animais foram submetidos à lesão do nervo ciático e tratados com reserpina $5 \mathrm{mg} / \mathrm{kg}$ VO em intervalos de $72 \mathrm{~h}$, durante 15 dias e com amitriptilina $5 \mathrm{mg} / \mathrm{kg} \mathrm{VO}$, diariamente, durante 15 dias $(\mathrm{n}=05)$.

Os animais foram submetidos à ligadura do nervo ciático sob anestesia com pentobarbital sódico $(45 \mathrm{mg} / \mathrm{kg}$, intraperitoneal). $\mathrm{O}$ nervo ciático direito do rato foi exposto e um segmento de 5-7 $\mathrm{mm}$ foi dissecado. Quatro ligaduras com fio de sutura catgut cromado 4-0 tipo C, com intervalos de $1 \mathrm{~mm}$ entre si, foram realizadas ao redor do nervo ${ }^{5}$.

Após a lesão do nervo ciático e tratamento farmacológico, todos os animais, tratados e controles, foram submetidos ao teste para percepção da sensibilidade (hiperalgesia). O teste consiste em tocar a região plantar da pata traseira direita (tratada) e esquerda (controle) dos animais com filamentos de espessura padronizada os chamados filamentos de Von Frey ${ }^{6}$. O levantar da pata ao toque indica sensibilidade. A espessura do filamento foi anotada e os resultados analisados estatisticamente. Os animais foram submetidos ao teste de Von Frey 15 dias após a ligadura do ciático. Foram feitas duas medidas, em intervalos de 3 dias. Depois do teste de Von Frey, todos os animais foram submetidos ao teste da formalina modificado injetada na pata ipsilateral a ligadura do nervo ciático. 


\section{Teste da formalina modificado}

Antes do procedimento o animal era colocado em uma câmara de vidro de $30 \times 30 \times 30 \mathrm{~cm}$, por 15 minutos, para ambientalizar ao local de estudo. Atrás da câmara foi colocado um espelho, em ângulo de $45^{\circ}$, para facilitar a visualização das elevações de patas em todas as direções.

O teste consistiu na injeção de $50 \mu \mathrm{L}$ da solução de formalina, na concentração de $2 \%$ no dorso da pata traseira dos ratos produzindo resposta nociceptiva bifásica. A primeira fase foi observada durante os primeiros 5 minutos após a injeção e a segunda fase, iniciada após 15 minutos e se estendeu por 40 a 50 minutos. A primeira fase foi interpretada como sendo devida à ativação aguda dos nociceptores periféricos, enquanto a segunda como resultante da resposta inflamatória aguda ou pela sensibilização central. O período entre as duas fases da resposta nociceptiva identificado como fase de inatividade, a qual é atribuída o envolvimento de um mecanismo antinociceptivo central ${ }^{7}$.

Todas as elevações da pata não relacionadas à marcha foram consideradas, independente do tempo que a mesma permaneceu elevada. A contagem foi realizada continuamente durante 60 minutos e a cada 5 minutos era anotado o número parcial de elevações.

Para análise estatística dos resultados obtidos, foi utilizada a Análise de Variância para amostras independentes, seguida do teste de Bonferroni. Adotou-se o nível de significância menor que $5 \%(\mathrm{p}<0,05)$.

\section{RESULTADOS}

Não houve alteração do limiar de dor nos animais de todos os grupos, com os testes feitos com os filamentos de Von Frey, realizados a cada três dias, durante 15 dias. A ligadura do ciático reduziu o número de elevações da pata direita dos animais tratados em comparação com os animais controles, durante os cinco primeiros minutos do teste da formalina (Fase I - nocicepção periférica). O tratamento com amitriptilina eliminou esta diferença. Foi observada redução do número de elevações da pata em comparação com os controles nos animais reserpinados. O tratamento com amitriptilina nos animais reserpinados também eliminou a diferença anteriormente observada (Gráfico 1).

Do sexto ao $20^{\circ}$ minutos (fase de inatividade ou intermediária - mecanismo nociceptivo central) do teste da formalina, a ligadura do ciático aumentou o número de elevações de pata nos animais testados em comparação com os animais controle. O tratamento com amitriptilina eliminou esta diferença. A reserpina não interferiu com a via descendente inibitória da dor, mas, o tratamento com reserpina e amitriptilina diminuiu o número de elevações de pata da fase 2 do teste da formalina (Gráfico 2).

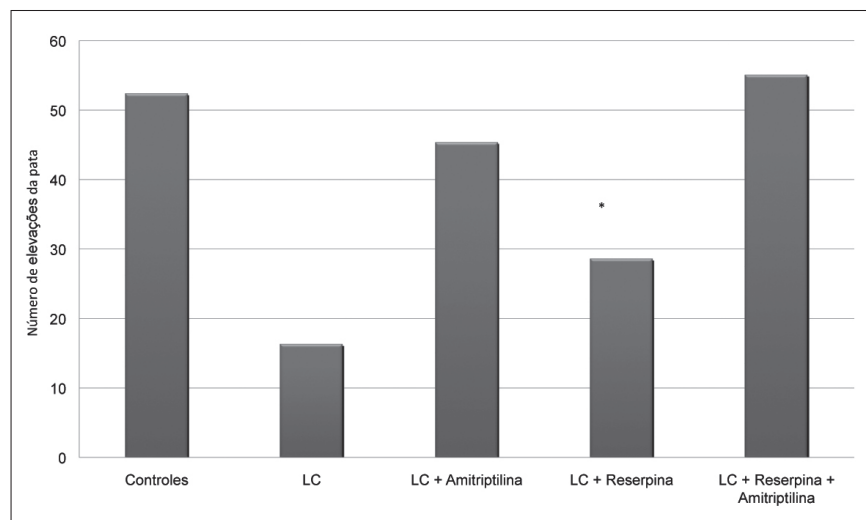

Gráfico 1 - Elevações da pata direita de ratos submetidos ao teste da formalina modificado, durante os cinco primeiros minutos (Fase I). Controles: ratos sem tratamento $(\mathrm{n}=04)$; $\mathrm{LC}$ : ratos submetidos à ligadura do nervo ciático $(\mathrm{n}=05) ; \mathrm{LC}+\mathrm{A}$ : ratos submetidos à ligadura do nervo ciático $(\mathrm{n}=05)$, tratados com amitriptilina $5 \mathrm{mg} / \mathrm{kg}$, diariamente, $\mathrm{VO}$, durante 15 dias; $\mathrm{LC}+\mathrm{R}$ : ratos submetidos à ligadura do nervo ciático $(\mathrm{n}=05)$, tratados com reserpina $(5 \mathrm{mg} / \mathrm{kg}), \mathrm{VO}$, em intervalos de $72 \mathrm{~h}$, durante 15 dias; $\mathrm{LC}+\mathrm{AR}$ : ratos submetidos à ligadura do nervo ciático $(\mathrm{n}=05)$, tratados com reserpina $(5 \mathrm{mg} / \mathrm{kg})$, $\mathrm{VO}$, em intervalos de $72 \mathrm{~h}$, durante 15 dias e com amitriptilina $(5 \mathrm{mg}$ / $\mathrm{kg}$ ), diariamente, $\mathrm{VO}$, durante 15 dias.

$* \mathrm{p}<0,05$ em comparação com o grupo C, LC + A ou LC+AR.

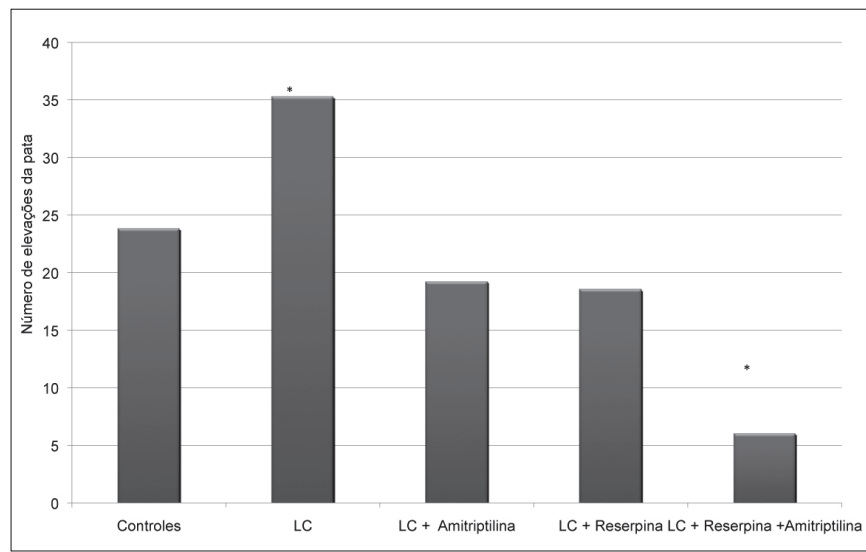

Gráfico 2 - Elevações da pata direita de ratos submetidos ao teste da formalina modificado, durante o sexto ao vigésimo minutos (Fase intermediária).

Controles: ratos sem tratamento $(\mathrm{n}=04)$; $\mathrm{LC}$ : ratos submetidos à ligadura do nervo ciático $(\mathrm{n}=05)$; $\mathrm{LC}+\mathrm{A}$ : ratos submetidos à ligadura do nervo ciático $(\mathrm{n}=05)$, tratados com amitriptilina $(5 \mathrm{mg} / \mathrm{kg})$, diariamente, $\mathrm{VO}$, durante 15 dias; $\mathrm{LC}+\mathrm{R}$ : ratos submetidos à ligadura do nervo ciático $(\mathrm{n}=05)$, tratados com reserpina $5 \mathrm{mg} / \mathrm{kg}, \mathrm{VO}$, em intervalos de $72 \mathrm{~h}$, durante 15 dias; $\mathrm{LC}+\mathrm{AR}$ : ratos submetidos à ligadura do nervo ciático $(\mathrm{n}=05)$, tratados com reserpina $(5 \mathrm{mg} / \mathrm{kg})$, $\mathrm{VO}$, em intervalos de $72 \mathrm{~h}$, durante 15 dias e com amitriptilina $(5 \mathrm{mg}$ / $\mathrm{kg}$ ), diariamente, $\mathrm{VO}$, durante 15 dias.

$* \mathrm{p}<0,05$ em comparação com o grupo C. 
A ligadura do ciático reduziu o número de elevações da pata nos animais na fase 2 (resposta inflamatória ou sensibilização central) do teste da formalina. $\mathrm{O}$ tratamento com amitriptilina restaurou a resposta. A administração de reserpina reduziu o número de elevações das patas. Não se observou aumento das elevações da pata após a reserpina + amitriptilina (Gráfico 3).

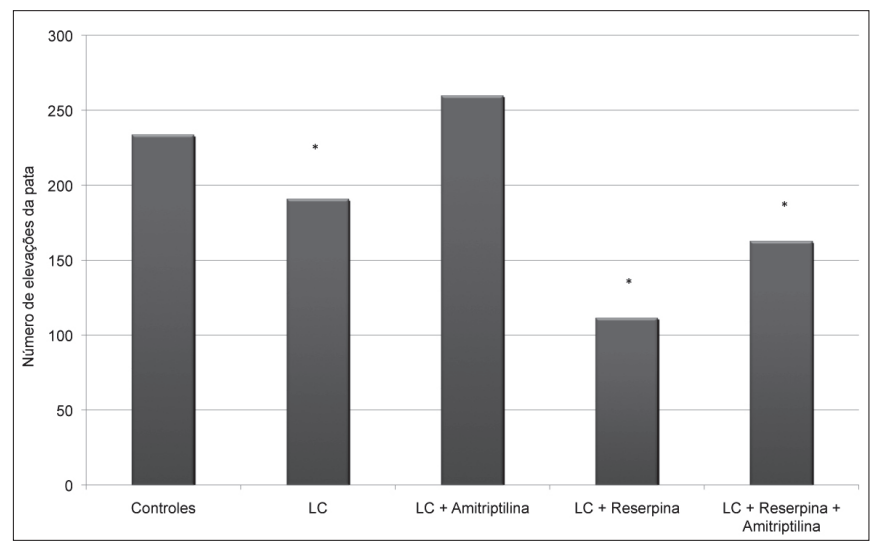

Gráfico 3 - Elevações da pata direita de ratos submetidos ao teste da formalina modificado, durante o $20^{\circ}$ ao $60^{\circ}$ minuto (Fase 2).

Controles: ratos sem tratamento $(\mathrm{n}=04)$; $\mathrm{LC}$ : ratos submetidos à ligadura do nervo ciático $(\mathrm{n}=05) ; \mathrm{LC}+\mathrm{A}$ : ratos submetidos à ligadura do nervo ciático $(\mathrm{n}=05)$, tratados com amitriptilina $(5 \mathrm{mg} / \mathrm{kg})$, diariamente, $\mathrm{VO}$, durante 15 dias; $\mathrm{LC}+\mathrm{R}$ : ratos submetidos à ligadura do nervo ciático $(\mathrm{n}=05)$, tratados com reserpina $(5 \mathrm{mg} / \mathrm{kg}), \mathrm{VO}$, em intervalos de $72 \mathrm{~h}$, durante 15 dias; $\mathrm{LC}+\mathrm{AR}$ : ratos submetidos à ligadura do nervo ciático $(\mathrm{n}=05)$, tratados com reserpina $(5 \mathrm{mg} / \mathrm{kg})$, $\mathrm{VO}$, em intervalos de $72 \mathrm{~h}$, durante 15 dias e com amitriptilina $(5 \mathrm{mg} /$ $\mathrm{kg}$ ), diariamente, $\mathrm{VO}$, durante 15 dias.

$* \mathrm{p}<0,05$ em comparação com o grupo C

\section{DISCUSSÃO}

A dor neuropática é caracterizada por alterações sensoriais como sensação desagradável anormal, aumento da resposta ao estímulo doloroso, ou dor em resposta a um estímulo que normalmente não causaria dor, respectivamente disestesia, hiperalgesia e alodínia ${ }^{8}$.

A ligadura do nervo ciático deveria ter provocado alterações no comportamento dos animais, tais como defesa, lambidas excessivas e evitar apoiar pata lesada, além de hiperalgesia mecânica e térmica, desenvolvidas após a segunda semana da cirurgia ${ }^{9}$. O estímulo lesivo é conduzido da periferia para o sistema nervoso central por meio de fibras mielinizadas e amielínicas de diferentes espessuras. Cada tipo de fibra está relacionada a condução de sensações específicas, localizadas ou difusas ${ }^{10}$. A avaliação da hiperalgesia ou alodínia mecânica, no presente estudo, foi testada com os filamentos de Von Frey. Como não foi observada resposta nos animais, é possível supor que houve lesão no ciático decorrente do procedimento cirúrgico, que prejudicou a sensibilidade mecânica. Os animais foram então submetidos ao teste da formalina, que avalia a dor após exposição à agente químico.

Os animais submetidos à ligadura do ciático apresentaram menor resposta em comparação com os controles na primeira fase do teste da formalina. A primeira fase está relacionada com a nocicepção ${ }^{7}$. O tratamento com reserpina manteve esta resposta. Estes resultados estão de acordo com os apresentados em trabalho anterior, em que animais intactos, sem procedimento cirúrgico, tratados com reserpina, apresentaram padrão de resposta inalterado na primeira fase do teste, o que permitiu inferir que o fármaco não interfere com a transdução do sinal doloroso ${ }^{11}$.

Normalmente, neurônios sensoriais dos gânglios dorsais da medula espinhal não são inervados pelas fibras simpáticas. Inervação anormal pelas fibras simpáticas após lesão do ciático foi descrita, e estudos subsequentes demonstraram este fato em vários modelos de dor experimental e pode ocorrer se há inflamação ou compressão local do corno posterior da medula ${ }^{12}$. $\mathrm{O}$ aumento da inervação simpática poderia explicar porque o tratamento com amitriptilina restaurou a resposta à formalina, aumentando-a, na presença ou ausência de reserpina, nos animais submetidos à ligadura do ciático. A sensibilização dos nociceptores depende do tipo da fibra, da intensidade do estímulo e dos mediadores envolvidos ${ }^{10}$. A ligadura do ciático poderia ter causado aumento da inervação simpática, que poderia ser detectada com o aumento na concentração de noradrenalina, pelo tratamento com amitriptilina.

A fase intermediária do teste da formalina está relacionada com a inibição central da dor ${ }^{7}$. A reserpina também não interfere com a fase intermediária do teste da formalina ${ }^{11}$.

A análise da fase intermediária do teste da formalina, que avalia a via descendente inibitória da dor, evidencia que a ligadura do ciático aumentou a resposta dolorosa. Diversos autores têm demonstrado que o estímulo lesivo contínuo aumenta a liberação de mediadores no sistema nervoso central, dentre eles a neurotensina ${ }^{13}$ ou altera receptores $\mathrm{NMDA}^{14}$. O estímulo álgico crônico, devido à ligadura do ciático, poderia ter alterado a expressão destes mediadores e receptores. Além disto, a sensibilização de receptores envolvidos na transdução do sinal doloroso ou o aumento da atividade de enzimas como a óxido nítrico sintase ${ }^{15}$ não pode ser descartada.

A fase 2 do teste da formalina analisa a resposta álgica, potencializada pelos mediadores da resposta inflamatória. A ligadura do ciático reduziu esta resposta, o que 
está de acordo com a hipótese de que houve alteração da transdução do sinal doloroso como anteriormente analisado. O tratamento com amitriptilina aumentou o número de elevações da pata, porém após a reserpina, ocorreu redução do número de elevações da pata, que não foi restaurado pela amitriptilina.

O antidepressivo tricíclico amitriptilina, apresentou efeitos anti-inflamatórios sistêmicos e centrais em modelo de dor induzida pela aplicação de carragenina, principalmente pela inibição da migração de polimorfonucleares e da liberação de interleucina-1 e fator de necrose tumoral alfa no local da inflamação ${ }^{16}$. Apesar do teste da formalina também provocar lesão tecidual e ativação da resposta inflamatória, a ligadura do ciático parece envolver mecanismos de plasticidade neuronal, que aumentam a sensibilidade dos nociceptores aos mediadores da resposta inflamatória aguda.

Portanto, a ligadura do ciático reduziu a resposta nociceptiva. $\mathrm{O}$ tratamento com reserpina não interferiu com a resposta álgica neste modelo experimental, na fase 1 do teste da formalina. A administração de amitriptilina restaurou a resposta álgica na fase 1 do teste da formalina, indicando potencialização da nocicepção periférica. A administração de amitriptilina reduziu o número das elevações das patas, observada durante a fase intermediária do teste da formalina, na ausência ou na presença de reserpina, indicando potencialização da resposta da via descendente inibitória da dor. A ligadura do ciático reduziu a resposta na fase 2 do teste da formalina. A amitriptilina restaurou a resposta anteriormente observada.

\section{CONCLUSÃO}

O tratamento com amitriptilina e reserpina permite sugerir que, no modelo de lesão neural periférica, a noradrenalina participa da transdução do sinal lesivo, na modulação da via descendente inibitória da dor e na nocicepção induzida pelo processo inflamatório. A participação dos outros mediadores da resposta inflamatória e da serotonina deve ser considerada.

\section{REFERÊNCIAS}

1. Dharmshaktu P, Tayal V, Kalra BS. Efficacy of antidepressants as analgesics: a review. J Clin Pharmacol 2011;17 [Epub ahead of print].

2. Millan MJ. Descending control of pain. Prog Neurobiol 2002;66(6):355-474.

3. Sawynok J, Esser MJ, Reid AR. Antidepressants as analgesics: an overview of central and peripheral mechanisms of action. J Psychiatry Neurosci 2001;26(1):21-9. 4. Pereira RIC, Cecarelli MJC, Oliveira AS. Antidepressivos e tratamento da dor crônica. Rev Bras Anestesiol 1989;39(6):449-55.

5. Bennett GJ, Xie YK. A peripheral mononeuropathy in rat that produces disorders of pain sensation like those seen in man. Pain 1988;3(1):87-107.

6. Pitcher GM, Ritchie J, Henry JL. Paw withdrawal threshold in the von Frey hair test is influenced by the surface on which the rat stands. 1999;87(2):185-93.

7. Abbott FV, Franklin KB, Westbrook RF. The formalin test: scoring properties of the first and second phases of the pain response in rats. Pain 1995;60(1):91-102.

8. Woolf CJ, Mannion RJ. Neuropathic pain: aetiology, symptoms, mechanisms, and management. Lancet 1999;353(9168):1959-64.

9. De Vry J, Kuhl E, Franken-Kunkel P, et al. Pharmacological characterization of the chronic constriction injury model of neuropathic pain. Eur J Pharmacol 2004;491(2-3):137-48.

10. Perl ER. Pain mechanisms: a commentary on concepts and issues. Prog Neurobiol 2011;94(1):20-38.

11. Marton BCV, Honda FCS, Pires OC, Posso IP, Cusma Pelógia NC. Efeito do tratamento com reserpina sobre a dor aguda em ratos submetidos ao teste da formalina modificado. Rev Dor 2009;10(4):325-30.

12. Xie W, Strong JA, Zhang JM. Increased excitability and spontaneous activity of rat sensory neurons following in vitro stimulation of sympathetic fiber sprouts in the isolated dorsal root ganglion. Pain 2010;151(2):447-59.

13. Williams FG, Beitz AJ. Chronic pain increases brainstem proneurotensin/neuromedin-N mRNA expression: a hybridization-histochemical and immunohistochemical study using three different rat models for chronic nociception. Brain Res 1993;14;611(1):87-102.

14. Renno WM. Prolonged noxious stimulation increases periaqueductal gray NMDA mRNA expression: a hybridization study using two different rat models for nociception. Ir J Med Sci 1998;167(3):181-92.

15. Freire MA, Guimarães JS, Leal WG, et al. Pain modulation by nitric oxide in the spinal cord. Front Neurosci 2009;3(2):175-81.

16. Sadeghi H, Hajhashemi V, Minaiyan M, et al. A study on the mechanisms involving the anti-inflammatory effect of amitriptyline in carrageenan-induced paw edema in rats. Eur J Pharmacol 2011;667(1-3):396-401.

Apresentado em 16 de maio de 2011.

Aceito para publicação em 02 de setembro de 2011. 